\title{
Efficacy of Early Use of Ivabradine Alone Versus Beta Blockers in Patients with Acute Heart Failure
}

\author{
Mohamed A. Elian, Elsayed Abd Elkhalek, Islam H. Rashid, Hany H. Ebaid
}

\begin{abstract}
Department of cardiology, Benha faculty of medicine, Banha University, Egypt.
\end{abstract}

Correspondence to: Islam $\mathrm{H}$. Rashid. Department of cardiology, Benha faculty of medicine, Banha University, Egypt

Email:

islamhassan2021@yahoo.com

Received: 1 July 2021

Accepted: 26 November 2021

\begin{abstract}
Background: Acute heart failure (AHF) is a life-threatening medical condition requiring urgent evaluation and treatment, this study aimed to evaluate efficacy and safety of the early use of Ivabradine alone versus Beta blockers when tolerated in patients with acute heart failure. Methods: sixty of patients were included in this study and divided into two groups; Group 1(30 patients): prescribed beta-blockers, and Group 2 (30 patients) prescribed Ivabradine, All patients were subjected to full history taking, complete clinical examination, 12 lead surface ECG, full echocardiography study, Follow up of Patients after one month: by Exercise Tolerance Assessed by 6 Minute Walking Test (6MWD), Quality of life, Heart rate, and NYHA class. Results: Group (1) included $24(80 \%)$ males \& $6(20 \%)$ females, their median age was 60.0 years, Group (2) included 23 (76.7\%) males \& 7 (23.3\%)
\end{abstract} females, their Median age was 59.5 years, There was no statistical significant difference between two groups regarding NYHA class before and after intervention( $\mathrm{P}>0.05$ for both), 6MWD before and after 1 month. HR before and after the walk test either at baseline or after $1 \mathrm{~m}$ of treatment ( $\mathrm{P}>0.5$ for all), dyspnea before and after the walk test either at baseline or after $1 \mathrm{~m}$ of treatment ( $\mathrm{P}>0.5$ for all), or fatigue before and after the walk test either at baseline or after 1 month of treatment ( $\mathrm{P}>0.5$ for all). Conclusion: Both groups achieved comparable reduction in HR with improvement in functional capacity and exercise tolerance which can be translated to better prognosis.

Keywords: Ivabradine; Beta Blockers; Heart Failure; HF 


\section{Introduction}

Acute heart failure (AHF) refers to rapid onset or worsening of symptoms and/or signs of HF. It is a life-threatening medical condition requiring urgent evaluation and treatment, typically leading to urgent hospital admission. AHF may present as a first occurrence (de novo) or, more frequently, as a consequence of acute decompensation of chronic $\mathrm{HF}(\mathrm{CHF})$ and may be caused by primary cardiac dysfunction or precipitated by extrinsic factors, often in patients with CHF (1).

Ivabradine should be considered to reduce the risk of HF hospitalization or cardiovascular death in symptomatic patients with $\mathrm{LVEF} \leq 35 \%$, in sinus rhythm and a resting heart rate $\geq 70$ despite treatment with an evidence-based dose of betablocker (or maximum tolerated dose below that) or, who are unable to tolerate or have contra-indications for a beta-blocker. Patients should also receive an ACE-I (or ARB) and an MRA (or ARB) (2). The association of ivabradine and atenolol has been proven effective in increasing exercise tolerance in patients with ischemic heart disease (3).

The aim of the present study is to evaluate efficacy and safety of the early use of
Ivabradine alone versus Beta blockers when tolerated in patients with acute heart failure, as a strategy of heart rate control, improving exercise tolerance and improving quality of life .

\section{Patients and methods}

This was a randomized, prospective study that was conducted in Nasser Institute hospitals \& Benha University hospitals, cardiology department in a period starting from November 2019 to March 2020. The study included 60 adult patients with acute heart failure (either acute exacerbation of chronic heart failure or Denovo) divided into two groups;

Group 1: It included 30 patients with symptoms and signs of acute heart failure who received beta-blockers according to the tolerated dose and type with other antifailure treatment after stabilization of the patients.

Group 2: It included 30 patients with symptoms and signs of acute heart failure who received Ivabradine $5-7.5 \mathrm{mg}$ twice daily with other anti-failure treatment after stabilization of the patients. 


\section{Inclusion criteria:}

- Sinus rhythm

- $\quad H R \geq 70 \mathrm{bpm}$

- Hospitalization for AHF (1).

- Ejection fraction $\leq 40 \%$.

\section{Exclusion criteria:}

- Systolic blood pressure $<85$ $\mathrm{mmHg}$ (cardiogenic shock) or need for positive inotropes.

- Acute myocarditis.

- Primary valvular disease requiring surgery.

- Atrial fibrillation or flutter.

- Second or third degree atrio-ventricular blockade.

- Long QT syndrome.

- Severe pulmonary disease.

- Hepatic failure.

- Creatinine > $2.5 \mathrm{mg} / \mathrm{dl}$ or patients on Hemodialysis.

- Pregnancy or lactation.

- Patients who were not controlled on single therapy ( BBs or Ivabradine) as tolerated to the guidelines recommended doses.

All patients were subjected to full history taking, complete clinical examination, 12 lead surface ECG, full echocardiography study; each patient was offered a full echocardiography study For each patient ejection fraction was assessed by Modified Simpson`s method (biplane method of disks) a modality requiring area tracings of $\mathrm{LV}$ cavity. By tracing the endocardial border in both the apical four-chamber and twochamber views in end-systole and enddiastole (Kosaraju et al, 2020), M-Mode , left ventricular dimensions were measured, segmental wall motion abnormalities and, diastolic function.

Follow up of Patients after one month:

- Exercise Tolerance Assessed by 6 Minute Walking Test (6MWD) (4).

The test was performed according to American Thoracic Society (ATS) statement 2002, after history taking, examination, ECG \& performing an echocardiography for the patient. Immediately After stabilization of the patient, the test was performed.

Before the test, the patient sit on a chair near the starting position where blood pressure \& pulse were measured, baseline dyspnea and overall fatigue were recorded using the Borg scale \& the worksheet was fulfilled.

The scale was shown to the patient and the patient was asked to record his level of shortness of breath and level of fatigue using the scale. 
At the end of the exercise, the patient was reminded of the breathing number and fatigue number that he chose before the exercise and he was asked to grade both again.

The test was performed in CCU where all cardiac resuscitation tools were available.

We used a 15 meter walking corridor with marks on the wall every 3 meters. The patient had to turn around at the end of each 15 meters to complete 1/2 lap at 60 meters.

The turnaround point was marked with a chair at the end of the corridor.

- Quality of life (Minnesota living with heart failure questionnaire) (5)

It is formed by 21 items that contemplate the physical, socioeconomic and psychological limitations that patients frequently reported connected with their heart failure (5)

Participating patients were asked to complete the MLHFQ at baseline and at the end of the study. For Each of the 21 questions the patients were asked to indicate how much a possible effect of heart failure prevented them from living as they wanted during the past month (It is important to explain previously to patients that they should consider the last month to answer the questionnaires.), using a scale from 0 (not present or no effect), 1 (very little), 2, 3, 4, or 5 (very much).

The score of the phvsical dimension corresponds to the sum of eight questions (\# 2, 3, 4, 5, 6, 7, 12 and 13) related to dyspnea and fatigue.

The score of the emotional dimension is formed by five questions (\# 17, 18, 19, 20 and 21).

The remaining questions $(\# 1,8,9,10$, $11,14,15$ and 16) plus the physical and emotional dimensions determined the total score. Higher scores indicate worse HRQOL (Health- Related Quality of Life)

- Heart rate

- NYHA class (6).

Written consents according to Helsinki declaration were obtained from all patients before participation in the study that was approved by the ethical committee of Benha faculty of medicine.

\section{Statistical Analysis}

Data were analysed using SPSS software, version 22.0 (IBM, Armonk, NY, USA) and the following were .Categorical data were presented as number and percentages, Chi square $\left(\chi^{2}\right)$, Fisher's exact tests and Mc- 
Nemer's and marginal homogeneity tests. Quantitative data were tested for normality using Shapiro-Wilks test assuming normality at $\mathrm{P}>0.05$. Normally distributed variables were expressed as mean \pm standard deviation. Non parametric data were presented as median and Inter -quartilep' range (IQR).

\section{Results}

Group (1) included $24(80 \%)$ males \& 6 (20\%) females, their median age was 60.0 years, average BMI of $29.23 \pm 3.18 \mathrm{~kg} / \mathrm{m}^{2}$. Group (2) included $23(76.7 \%)$ males \& 7 (23.3\%) females, their Median age was 59.5 years, Mean BMI of $30.27 \pm 4.17$ $\mathrm{kg} / \mathrm{m}^{2}$, with no statistically significant difference between the two groups as regard to sex, Age, BMI. table 1

There was no statistical significant difference between two groups regarding NYHA class before intervention also there was no statistical significant difference between two groups regarding NYHA after intervention. ( $\mathrm{P}>0.05$ for both), while there is highly statistical significant improvement between before and after intervention as regard NYHA class within each group $(\mathrm{P}<0.001)$. table 2. 6MWD was comparable between the two groups either before or after 1 month with no statistically significant difference $(\mathrm{P}>0.05)$, but within each group, there was a highly significant increase; regarding group 1, the mean 6MWD was increased from 156.7 before to 273.7 after 1 month $(\mathrm{P}<0.001)$. regarding group 2 , it was increased from 147.3 to $268.9(\mathrm{P}<0.001)$. table 3

Regarding the median values of HR before and after the walk test between the two groups either at baseline or after $1 \mathrm{~m}$ of treatment $(\mathrm{P}>0.5$ for all) with no statistically significant difference. But there was a significant difference between them regarding $\Delta$ increase in $\mathrm{HR}$ after treatment $(\mathrm{P}<0.05)$, where the median delta increase in HR was 20.0 in group 1 compared to 18.0 in group 2. Regarding comparisons within groups, the median HR was significantly increased after the walk test than before it in each group, either before treatment or $1 \mathrm{~m}$ after $(\mathrm{P}<0.05$ for all). Moreover, there was a significant decrease in the median before and after walk test HR after 1 month of treatment than baseline in each group ( $\mathrm{P}<0.001$, for both groups), table 4

On comparing between the studied groups regarding the median values of dyspnea before and after the walk test, we observed no significant difference either at baseline or after $1 \mathrm{~m}$ of treatment ( $\mathrm{P}>0.5$ for all). Also, 
there was no significant difference between them regarding $\Delta$ increase in dyspnea at baseline. But after $1 \mathrm{~m}$ of treatment, the median and IQR of delta increase in dyspnea were significantly higher in group 1 (3.0 (34)) than in group $2(3.0 \quad(2-3)) \quad \mathrm{P}<0.05$. Regarding comparisons within groups, the median and IQR of dyspnea were significantly increased after the walk test than before it in each group, either before treatment or $1 \mathrm{~m}$ after $(\mathrm{P}<0.05$ for all). Moreover, there was a significant decrease in the median values before and after walk test dyspnea after $1 \mathrm{~m}$ of treatment than baseline in each group $(\mathrm{P}<0.001$, for both groups),but improvement was was more among group 2 , table 5

Regarding the median values of fatigue before and after the walk test between the two groups either at baseline or after 1 month of treatment $(\mathrm{P}>0.5$ for all) with no statistically significant difference.Also, there was no significant difference between them regarding $\Delta$ increase in fatigue at baseline. But after $1 \mathrm{~m}$ of treatment, the median and IQR of delta increase in fatigue were significantly higher in group 1 (3.0 (2-4)) than in group $2 \quad(3.0 \quad(2-3)) \quad \mathrm{P}<0.05$. Regarding comparisons within groups, the median and IQR of fatigue were significantly increased after the walk test than before it in each group, either before treatment or $1 \mathrm{~m}$ after $(\mathrm{P}<0.05$ for all). Moreover, there was a significant decrease in the median values before and after walk test fatigue after $1 \mathrm{~m}$ of treatment than baseline in each group $(\mathrm{P}<0.001$, for both groups) ,but improvement was more among group 2. table 6

Table(1):Comparison between the two studied groups according to demographic data

\begin{tabular}{|c|c|c|c|c|c|c|c|}
\hline & & \multicolumn{2}{|c|}{$\begin{array}{l}\text { Group I } \\
(\mathbf{n}=\mathbf{3 0})\end{array}$} & \multicolumn{2}{|c|}{$\begin{array}{c}\text { Group II } \\
(\mathbf{n}=\mathbf{3 0})\end{array}$} & \multirow[t]{2}{*}{$\begin{array}{l}\text { Test of } \\
\text { Sig. }\end{array}$} & \multirow[t]{2}{*}{$\mathbf{p}$} \\
\hline & & No. & $\%$ & No. & $\%$ & & \\
\hline \multirow{2}{*}{ Sex } & Male & 24 & 80.0 & 23 & 76.7 & \multirow{2}{*}{$\begin{array}{l}\chi 2= \\
0.098\end{array}$} & \multirow[t]{2}{*}{0.754} \\
\hline & Female & 6 & 20.0 & 7 & 23.3 & & \\
\hline Age (years) & $\begin{array}{l}\text { Min. - Max. } \\
\text { Median (IQR) }\end{array}$ & \multicolumn{2}{|c|}{$\begin{array}{l}40.0-86.0 \\
60.0(52.0-66.0)\end{array}$} & \multicolumn{2}{|c|}{$\begin{array}{l}\mathbf{4 8 . 0}-\mathbf{8 7 . 0} \\
59.5(55.0-64.3)\end{array}$} & $\begin{array}{l}\mathrm{ZM} \Omega \mathrm{Y}= \\
0.27\end{array}$ & 0.78 \\
\hline BMI $\left(\mathrm{kg} / \mathrm{m}^{2}\right)$ & $\begin{array}{l}\text { Min. - Max. } \\
\text { Mean } \pm \text { SD. }\end{array}$ & \multicolumn{2}{|c|}{$\begin{array}{l}25.0-36.0 \\
29.23 \pm 3.18\end{array}$} & \multicolumn{2}{|c|}{$\begin{array}{l}23.0-38.0 \\
30.27 \pm 4.17\end{array}$} & $\tau=1.079$ & 0.285 \\
\hline
\end{tabular}

$\mathrm{Z}$ MWU $=$ Standardized $\mathrm{Z}$ value of Mann Whitney U test, $\chi 2$ :Chi square test. $\mathrm{t}$ : Student $\mathrm{t}$-test , p: $\mathrm{p}$ value for comparing between the studied groups 
Table (2): Comparing the studied groups according to NYHA class at baseline and after 1 month of treatment.

\begin{tabular}{|c|c|c|c|c|c|c|}
\hline \multirow[t]{2}{*}{ NYHA class } & \multicolumn{2}{|c|}{$\begin{array}{l}\text { Group I } \\
(\mathbf{n}=\mathbf{3 0})\end{array}$} & \multicolumn{2}{|c|}{$\begin{array}{c}\text { Group II } \\
(\mathbf{n}=\mathbf{3 0})\end{array}$} & \multirow[t]{2}{*}{$\chi^{2}$} & \multirow[t]{2}{*}{$\mathbf{p}$} \\
\hline & No. & $\%$ & No. & $\%$ & & \\
\hline \multicolumn{7}{|l|}{ At baseline } \\
\hline I & 0 & 0.0 & 0 & 0.0 & \multirow{4}{*}{1.832} & \multirow{4}{*}{0.176} \\
\hline II & 0 & 0.0 & 0 & 0.0 & & \\
\hline III & 17 & 56.7 & 22 & 73.3 & & \\
\hline IV & 13 & 43.3 & 8 & 26.7 & & \\
\hline \multicolumn{7}{|c|}{ After 1-Month } \\
\hline I & 13 & 43.3 & 9 & 30.0 & $\mathrm{FET}=$ & ${ }^{\mathrm{MC}} \mathrm{p}=$ \\
\hline II & 15 & 50.0 & 20 & 66.7 & 1.835 & 0.45 \\
\hline III & 2 & 6.7 & 1 & 3.3 & & \\
\hline IV & 0 & 0.0 & & 0.0 & & \\
\hline $\mathbf{p}_{1}$ & \multicolumn{2}{|c|}{$<0.001{ }^{*}$} & \multicolumn{2}{|c|}{$<0.001^{*}$} & & \\
\hline
\end{tabular}

$\chi^{2}$ : Chi square test FET $=$ Fisher's Exact test $\quad$ MC: Monte Carlo

$\mathrm{p}$ : $\mathrm{p}$ value for comparing between the studied groups

$\mathrm{p}_{1}$ : $\mathrm{p}$ value for Marginal Homogeneity Test for comparing between before and after in each group *: Statistically significant at $\mathrm{p} \leq 0.05$

Table (3):Comparison between the two studied groups according to 6MWD at baseline and after 1month

\begin{tabular}{|c|c|c|c|c|c|c|}
\hline 6MWD & $\begin{array}{l}\text { Group I } \\
(\mathbf{n}=\mathbf{3 0})\end{array}$ & & $\begin{array}{l}\text { Group II } \\
(\mathbf{n}=\mathbf{3 0})\end{array}$ & & St."t" & $\mathbf{P}$ \\
\hline \multirow[b]{2}{*}{ At base line } & Min. - Max & Mean \pm SD & Min. - Max & Mean \pm SD & & \\
\hline & $30.0-280.0$ & $\begin{array}{l}156.7 \pm \\
69.05\end{array}$ & $20.0-230.0$ & $\begin{array}{l}147.3 \pm \\
59.71\end{array}$ & 0.56 & 0.578 \\
\hline After 1 month & $80.0-400.0$ & $\begin{array}{l}273.7 \pm \\
98.98\end{array}$ & $150.0-380.0$ & $\begin{array}{l}268.9 \pm \\
55.12\end{array}$ & 0.22 & 0.823 \\
\hline Paired " $t$ " & 7.88 & & 14.2 & & & \\
\hline (P1) & $(<0.001, \mathrm{HS})$ & & $(<0.001, \mathrm{HS})$ & & & \\
\hline
\end{tabular}

$\mathrm{p}$ : $\mathrm{p}$ value for comparing between the studied groups

$\mathrm{p} 1$ : $\mathrm{p}$ value for Paired "t" test for comparing before and after 1month in each group HS= highly significant 
Table (4): Comparison between the two studied groups according to HR before and after 6MWD (at baseline \& after 1 month follow up).



ZMWU: Z value of Mann Whitney test

$\mathrm{p}$ : $\mathrm{p}$ value for comparing between the studied groups

$\mathrm{p}_{1}$ : $\mathrm{p}$ value for Wilcoxon signed ranks test for comparing HR before and after walk test in each group

$\mathrm{p}_{2}$ : comparing between HR at baseline and after 1month (Delta increases)

$\mathrm{p}_{3}$ : comparing HR before walk test between before and after 1 month of treatment.

$\mathrm{p}_{4}$ : comparing HR after walk test between before and after 1 month of treatment .

$\mathrm{S}=$ significant

$\mathrm{HS}=$ highly significant 
Table (5): Comparison between the two studied groups according to BORG dyspnea at baseline and after 1month of treatment.

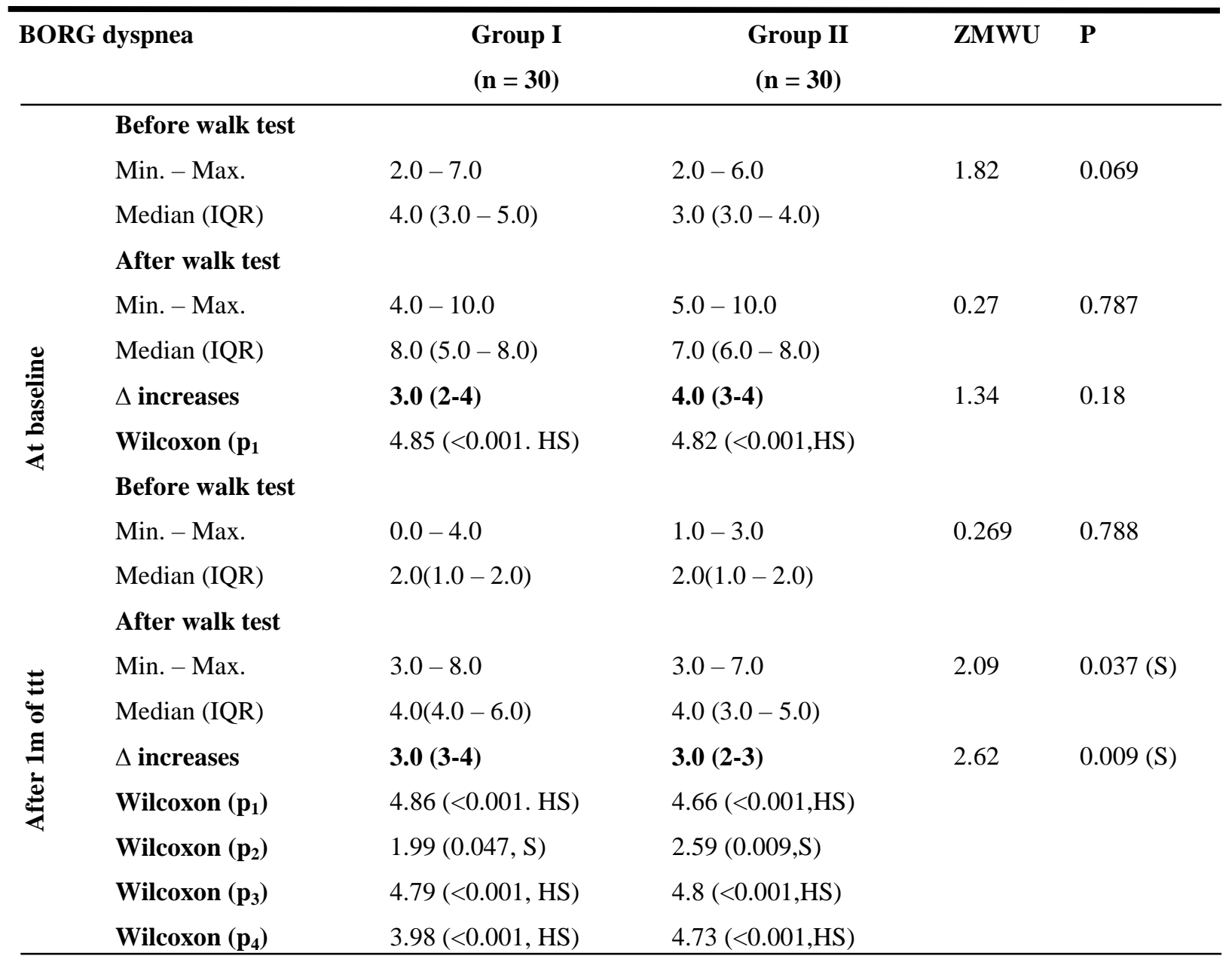

ZMWU: Z value of Mann Whitney test

$\mathrm{p}: \mathrm{p}$ value for comparing between the studied groups

$\mathrm{p}_{1}: \mathrm{p}$ value for Wilcoxon signed ranks test for comparing dyspnea before and after walk test in each group

$\mathrm{p}_{2}$ : comparing between dyspnea at baseline and after 1 month

(Delta increases)

$\mathrm{p}_{3}$ : comparing dyspnea before walk test between before and after 1 month of $\mathrm{ttt}$

$\mathrm{p}_{4}$ : comparing dyspnea after walk test between before and after 1month of ttt

$\mathrm{S}=$ significant

HS= highly significant 
Table (6): Comparison between the two studied groups according to BORG Fatigue at baseline and after 1-month of TTT.

\begin{tabular}{|c|c|c|c|c|c|c|}
\hline \multicolumn{2}{|c|}{ BORG fatigue } & \multirow{2}{*}{$\begin{array}{l}\text { Group } \\
(\mathbf{n}=\mathbf{3 0}) \\
\end{array}$} & \multirow[t]{2}{*}{1} & \multirow{2}{*}{$\begin{array}{l}\text { Group } 2 \\
(\mathbf{n}=\mathbf{3 0})\end{array}$} & \multirow[t]{2}{*}{ ZMWU } & \multirow[t]{2}{*}{$\mathbf{P}$} \\
\hline \multirow{9}{*}{ 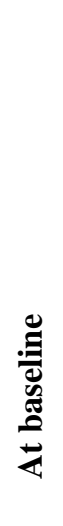 } & Before & & & & & \\
\hline & Min. - Max. & $2.0-7.0$ & & $2.0-7.0$ & 1.57 & 0.11 \\
\hline & Median (IQR) & $4.0(3.0-5.0)$ & & $3.5(3.0-4.0)$ & & \\
\hline & After & & & & & \\
\hline & Min. - Max. & $5.0-10.0$ & & $4.0-10.0$ & 0.69 & 0.49 \\
\hline & Median (IQR) & $8.0(6.0-8.0)$ & & $7.0(6.0-8.0)$ & & \\
\hline & $\Delta$ increases & $3.5(2-4)$ & & $4(2-4)$ & 0.26 & 0.79 \\
\hline & $\mathbf{p}_{1}$ & $4.84(<0.001, \mathrm{HS})$ & & $4.66(<0.001, \mathrm{HS})$ & & \\
\hline & Before & & & & & \\
\hline \multirow{10}{*}{ 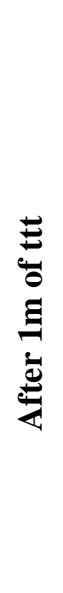 } & Min. - Max. & $0.0-4.0$ & & $1.0-3.0$ & 0.13 & 0.90 \\
\hline & Median (IQR) & $2.0(1.0-2.0)$ & & $2.0(1.0-2.0)$ & & \\
\hline & After & & & & & \\
\hline & Min. - Max. & $3.0-8.0$ & & $3.0-7.0$ & 2.11 & $0.035, \mathrm{~S}$ \\
\hline & Median (IQR) & $5.0(4.0-6.0)$ & & $4.0(4.0-5.0)$ & & \\
\hline & $\Delta$ increases & $3.0(2-4)$ & & $3.0(2-3)$ & 2.23 & $0.026, \mathrm{~S}$ \\
\hline & Wilcoxon $\left(p_{1}\right)$ & $4.82(<0.001, \mathrm{HS})$ & & $4.72(<0.001, \mathrm{HS})$ & & \\
\hline & Wilcoxon $\left(\mathbf{p}_{2}\right)$ & $2.01(0.044, \mathrm{~S})$ & & $2.26(0.025, \mathrm{~S})$ & & \\
\hline & Wilcoxon $\left(\mathbf{p}_{3}\right)$ & $4.78(<0.001, \mathrm{HS})$ & & $4.8(<0.001, \mathrm{HS})$ & & \\
\hline & Wilcoxon $\left(\mathbf{p}_{4}\right)$ & $3.85(<0.001, \mathrm{HS})$ & & $4.57(<0.001, \mathrm{HS})$ & & \\
\hline
\end{tabular}

ZMWU: Z value of Mann Whitney test

$\mathrm{p}$ : $\mathrm{p}$ value for comparing between the studied groups

$\mathrm{p}_{1}$ : $\mathrm{p}$ value for Wilcoxon signed ranks test for comparing fatigue before and after walk test in each group

$\mathrm{p}_{2}$ : comparing between fatigue at baseline and after 1 month

(Delta increases)

$\mathrm{p}_{3}$ : comparing fatigue before walk test between before and after 1month of treatment.

$\mathrm{p}_{4}$ : comparing fatigue after walk test between before and after 1 month of treatment.

$\mathrm{S}=$ significant

$\mathrm{HS}=$ highly significant

\section{Discussion}

In our study, There was no statistically significant difference between the two groups regarding NYHA class before and after intervention, while there is highly 
statistically significant difference between NYHA class before and after intervention in each group. In group I improvement from class III (56.7\%) and Class IV (43.3\%) to class I (43.3\%) and class II (50\%).In group II improvement from class III (73.3\%) and Class IV (26.7\%) to class I $(30.0 \%)$ and class II $(66.7 \%)$.

Our results were supported by another study (7) as they confirmed favorable effects of ivabradine administration alone on functional capacity as there was a highly significant improvement in the NYHA class of the patients in the current study population (there was a shift of patients from NYHA classes III and IV to NYHA classes I and II). Clinical data supporting the effects of ivabradine in HF is provided by an improvement in physical performance and increase in exercise capacity with addition of ivabradine.

Our study demonstrated that ivabradine administration was as effective as betablockers administration in AHF patients, as s significant reduction in resting $\mathrm{HR}$ after 4 weeks of treatment in both groups.

The degree of reduction in resting HR in our study was comparable to the data from the SHIFT study subgroup (17.83 beats/min at
28 days in the subgroup of baseline resting HR 75 beats/min) (8).

In our study, there was no statistically significant difference between the studied groups regarding the median values of BORG dyspnea and BORG Fatigue before and after the walk test (6MWD) either at baseline or after $1 \mathrm{~m}$ of treatment $(\mathrm{P}>0.5$ for all). Also, there was no significant difference between them regarding $\Delta$ increase in dyspnea at baseline. But after 1 month of treatment, the median and IQR of delta increase in dyspnea were significantly higher in group 1 (3.0 (3-4)) than in group 2 (3.0 (2-3)) $\mathrm{P}<0.05$. Also, there was no significant difference between them regarding $\Delta$ increase in fatigue at baseline. But after 1 month of treatment, the median and IQR of delta increase in fatigue were significantly higher in group 1 (3.0 (2-4)) than in group $2 \quad(3.0 \quad(2-3)) \quad \mathrm{P}<0.05$. Regarding comparisons within groups, the median and IQR of BORG dyspnea and BORG Fatigue (6MWD) were significantly increased after the walk test than before it in each group, either before treatment or $1 \mathrm{~m}$ after $(\mathrm{P}<0.05$ for all). Moreover, there was a significant decrease in the median values before and after walk test BORG dyspnea and BORG Fatigue (6MWD) after $1 \mathrm{~m}$ of treatment than baseline in each group 
( $\mathrm{P}<0.001$, for both groups $)$, but improvement was was more among group 2.

In another study (7), at baseline, there were no significant differences between both groups regarding the distance covered in the 6MWT with the assessment before and after the walk for the HR and Borg scale dyspnea/fatigue score, with the exception of Borg scale dyspnea/fatigue score before that showed significantly worse results in Group $1(\mathrm{p}=0.02)$. When used, BB up-titrated as part of optimum medical therapy for AHF resulted in a significant improvement in all the studied parameters (NYHA class; 6MWT distance; $\mathrm{HR}$ and Borg scale dyspnea/fatigue score before and after the walk), except for the premature termination of the $6 \mathrm{MWT}$ that did not reach statistical significance.

The present study showed that there is no statistically significant difference between two groups as regard premature termination of 6MWT before and after 1month, and there is no statistically significant difference before and after 1 month in each group. there was no statistical significant difference between two groups regarding MLHFQ Total score either in before and after 1month.
Quality of life improvement in older patients with heart failure initiated on ivabradine: Results from the UK multi- centre LIVE:LIFE, prospective cohort study is a multi-centre, open-label, prospective observational cohort study consisting with 240 patients aged $>70$ years with $\mathrm{CHF}$ assessing health-related quality of life (HRQOL) in older patients with chronic heart failure (CHF) following initiation of ivabradine. The primary endpoint is change in Minnesota Living with Heart Failure Questionnaire (MLWHFQ) total score after 6 months. (9)

With respect to our patients with $\mathrm{HF}$, this means that our medication should not only prevent HF-related death and hospitalization but also improve QoL, which often is severely impaired due to the symptoms of HF. Further, our medication should not further deteriorate QoL by severe adverse events. And, we should know which target symptomatic and/or prognostic? - we have to achieve.

Having this in mind, ivabradine is a good candidate for a HF drug: its QoL profile is above average, and its side-effect profile is below average. Many HFrEF patients under standard medical treatment inclusive of beta-blocker have a resting heart rate of $\geq 75$ b.p.m. and therefore might benefit from 
additional ivabradine treatment. In these patients, a reduction of heart rate should be achieved by additional ivabradine to $\leq 60$ b.p.m. or at least a reduction by $>10$ b.p.m. within 4 weeks. If this goal can be achieved, then we can tell the patient that his cardiovascular mortality risk within the next 2.5 years will be lowered by $17 \%$, his $\mathrm{HF}$ mortality risk will be lowered by $39 \%$, his HF hospitalization risk will be lowered by $30 \%$ and his health-related QoL will probably improve. (10).

And also this was concordant with another study (11) who showed that Ivabradine safely reduced the resting heart rate of children with chronic HF and dilated cardiomyopathy and acute decompensation on top . Ivabradine's effect on heart rate was variable, highlighting the importance of dose titration. Ivabradine treatment improved left ventricular ejection fraction, and clinical status and QOL showed favorable trends. (Determination of the efficacious and safe dose of ivabradine in paediatric patients with dilated cardiomyopathy and symptomatic chronic heart failure from ages 6 months to 18 years.in spite of different patient category to be studied same results as ours denoting effective and safe drug in different age groups.
In the study of another study (7), There were no significant differences between both groups regarding the MLWHFQ and the distance covered in the 6MWT with the assessment before and after the walk for the HR and Borg scale dyspnea/fatigue score.

In addition, our study assessed the effect of ivabradine on exercise tolerance and heart rate changes with exercise and showed significant beneficial effect of ivabradine on exercise heart rate under the effect of ivabradine which was recently studied in AHF patients to the best of our knowledge.

Our results were concordant with another study (12) who found that The strategy of the early coadministration of ivabradine and beta-blockers during a decompensation episode of HFrEF is feasible and safe. It significantly and markedly reduced HR at 28 days and at 4 months following hospital discharge. Moreover, at 4 months, this therapeutic strategy was associated with a significant improvement of functional and biochemical parameters which can be related to the prognosis, such as left ventricular ejection fraction, BNP levels, and severity of symptoms of HF. A longer period of follow-up and a larger number of patients are necessary to determine whether these results translate into improved 
prognosis regarding the reduction of longterm events.

The present study confirmed favorable effects of ivabradine administration alone on functional capacity as there was a statistically highly significant improvement in the NYHA class of the patients in the current study population (there was a shift of patients from NYHA class III and IV to NYHA class I and II).

Clinical data supporting the effects of ivabradine in $\mathrm{HF}$ is provided by an improvement in physical performance and increase in exercise capacity with addition of ivabradine. The Systolic Heart Failure Treatment with the I(f) Inhibitor Ivabradine Trial (SHIFT), has demonstrated the importance of $\mathrm{HR}$ reduction with ivabradine for improvement of clinical outcomes of heart failure symptoms. (8)

\section{Conclusion}

The results of this study demonstrated the safety and efficacy of the early administration of ivabradine alone or betablockers alone (non inferiority) in AHF patients (both acutely decompensated as well as de novo). It significantly and markedly reduced $\mathrm{HR}$ at one month following hospital discharge. Moreover, at 1 month follow up, Both groups achieved 30 comparable reduction in $\mathrm{HR}$ with improvement in functional capacity and exercise tolerance which can be translated to better prognosis. We recommended longer period of follow up and larger number of patients to study the long term efficacy of either strategies.

\section{References:}

1. Ponikowski P, Jankowska EA. Pathogenesis and clinical presentation of acute heart failure. Rev Española Cardiol (English Ed. 2015;68(4):3317.

2. Swedberg K, Komajda M, Böhm M, Borer JS, Ford I, Dubost-Brama A, et al. Ivabradine and outcomes in chronic heart failure (SHIFT): a randomised placebo-controlled study. Lancet. 2010;376(9744):875-85.

3. Tardif J-C, Ponikowski P, Kahan T, Investigators A. Effects of ivabradine in patients with stable angina receiving beta-blockers according to baseline heart rate: an analysis of the ASSOCIATE study. Int $\mathbf{J}$ Cardiol. 2013;168(2):789-94.

4. Laboratories ATSC on PS for CPF. ATS statement: guidelines for the six-minute walk test. Am J Respir Crit Care Med. 2002;166:1117.

5. Heo S, Moser DK, Riegel B, Hall LA, Christman N. Testing a published model of health-related quality of life in heart failure. J Card Fail. 2005;11(5):372-9.

6. Yancy CW, Jessup M, Bozkurt B, Butler J, Casey DE, Drazner MH, et al. 2013 ACCF/AHA 
guideline for the management of heart failure: a report of the American College of Cardiology Foundation/American Heart Association Task Force on Practice Guidelines. J Am Coll Cardiol. 2013;62(16):e147-239.

7. Othman KMS, Mostafa MAR, Yosef AE, Abdeltawab AA. Safety and efficacy of off-label use of ivabradine in patients with acute heart failure. J Saudi Hear Assoc. 2019;31(4):179-87.

8. Borer JS, Böhm M, Ford I, Robertson M, Komajda M, Tavazzi L, et al. Efficacy and safety of ivabradine in patients with severe chronic systolic heart failure (from the SHIFT study). Am J Cardiol. 2014;113(3):497-503.

9. Zachariah D, Stevens D, Sidorowicz G, Spooner C, Rowell N, Taylor J, et al. Quality of life improvement in older patients with heart failure initiated on ivabradine: results from the UK multi-centre LIVE: LIFE prospective cohort study. Int J Cardiol. 2017;249:313-8.
10. Müller-Werdan U, Stöckl G, Werdan K. Advances in the management of heart failure: the role of ivabradine. Vasc Health Risk Manag. 2016;12:453.

11. Bonnet D, Berger F, Jokinen E, Kantor PF, Daubeney PEF. Ivabradine in children with dilated cardiomyopathy and symptomatic chronic heart failure. J Am Coll Cardiol. 2017;70(10):1262-72.

12. Hidalgo FJ, Anguita M, Castillo JC, Rodríguez S, Pardo L, Durán E, et al. Effect of early treatment with ivabradine combined with betablockers versus beta-blockers alone in patients hospitalised with heart failure and reduced left ventricular ejection fraction (ETHIC-AHF): a randomised study. Int J Cardiol. 2016;217:7-11.

To cite this article: Mohamed A. Elian, Elsayed Abd Elkhalek, Islam H. Rashid, Hany H. Ebaid. Efficacy of Early Use of Ivabradine Alone Versus Beta Blockers in Patients with Acute Heart Failure. BMFJ 2022:39 (1):17-31, DOI: 10.21608/bmfi.2021.83471.1435 